\title{
Reliability Analysis and Improvement of Debre Berhan Power Distribution Network by Using Fuzzy Logic Optimization Technique
}

\author{
Desta Tegegne Asradew \\ Department of Electrical and Computer Engineering, University of Debre Berhan, Debre Berhan., Ethiopia \\ Email address: \\ tegegn.desta439@gmail.com \\ To cite this article: \\ Desta Tegegne Asradew. Reliability Analysis and Improvement of Debre Berhan Power Distribution Network by Using Fuzzy Logic \\ Optimization Technique. American Journal of Electrical and Computer Engineering. Vol. 5, No. 2, 2021, pp. 45-55. \\ doi: $10.11648 /$ j.ajece.20210502.12
}

Received: June 1, 2021; Accepted: July 20, 2021; Published: August 2, 2021

\begin{abstract}
This paper presents determination and allocation optimal number of sectionalizer switches using fuzzy based approach to improve the reliability of Berhan power distribution network. My intention to present in this study on the reliability assessment and method of improving reliability is that Debre Berhan power distribution network has frequent instructions. To improve customer reliability of power distribution system different methods can be used. Thus to complete this study MATLAB Simulink models of distribution network initial and optimal number of sectionalizer switch allocation are developed. Sheno $15 \mathrm{kV}$ feeder of the distribution network is selected for simulation studies to test the efficiency of the proposed approach. Simulation studies using ETAP software are carried out reliability indies of distribution network with and without optimal number of switch allocation. The simulation results show optimal allocation of sectionalizer switches improve the reliabity indices such as SAIFI, SAIDI and expected energy not supplied (EENS) and evaluates the reliability of Debre Berhan power distribution network using analytical techniques, software simulation and level of optimization achievable through the application optimal placement of switches. At the result of optimal placement of sectionalizers switches for sheno $15 \mathrm{kV}$ feeder SAIFI is improved by $12.76 \%$ and SAIDI are $41.61 \%$. From the test result the proposed technique presents better interruption cost in comparison that of existing system $64,806.06 \$ / y r$. to $57,346.57 \$ / y r$. (which is $11.5 \%$ reduction) along with improvement in reliability indices and expected energy not supplied (EENS) was improved from 17828.014MWh/yr. to1533.75MWh/yr. (91.04\%).
\end{abstract}

Keywords: Distribution System Reliability, ETAP Software, Fuzzy Logic Optimization, Sectionalizers Switches

\section{Introduction}

One of the critical requirement of any distribution system is of continuity and quality of power supply to the consumers, which mainly depends on interruption profile, based on system topology and component reliability data. To improve customer reliability of power distribution system different methods can be used. As different researchers agreed to perform distribution system reliability improvement different approaches and techniques can be used [1].

Reliability indices are a statistical aggregation of reliability data for a well-designed set of loads, distribution system components $[2,3]$. The use of index to indicate the average number of times of power failure and power outage per year per one customer makes it possible to compare between different systems and can also be targeted [4]. Reliability evaluation is the ultimate goal of reliability analysis which should be answered the question like: is the system reliable enough? Which scheme will be effective? And where high capital will be spent to improve the system? Reliability in power system can be divided in to two basic aspects: historical and predictive. The predictive reliability is then followed to predict the change in reliability measures after a change in system configuration or any implement strategy is planned to be implemented [3]. Distribution system reliability evaluation is able to predict the interruption profile of a distribution system based on system topology and component reliability data [5]. And optimization of both protection device and DGs' location may be performed in the planning stage of the feeder topology [6, 7]. Distribution system reliability indices can be determined as: 


$$
\begin{gathered}
\text { SAIFI }=\frac{\text { Total Number of Customer Interruption }}{\text { Total Number of Customers Served }}=\frac{\Sigma\left(\lambda_{i} \mathrm{~N}_{i}\right)}{\Sigma \mathrm{N}_{i}} \\
\text { SAIDI }=\frac{\text { Sum of Customer Interruption Durations }}{\text { Total Number of Customers }} \\
\text { CAIDI }=\frac{\text { Sumof Customer Interruption Durations }}{\text { Total Number of Customers Interruptions }}=\frac{\text { SAIDI }}{\text { SAIFI }} \\
\text { EENS }=\sum \mathrm{L}_{\mathrm{i}} * \mathrm{U}_{\mathrm{i}}
\end{gathered}
$$

I have collected data of intruption Debre Berhan distribution to determine the test feeder for applying the proposed method as indicated in table 1, that the ranking of cause of power interruption. This table could illustrate Sheno $(15 \mathrm{kV})$ is leading by un known cuase of power outage and hence this feeder must be consider for further study and applying the approparate improvement methods.

Table 1. The major cause of power interruption for each four [7] feeders.

\begin{tabular}{lllllll}
\hline \multirow{2}{*}{ Feeder } & \multicolumn{2}{l}{ Major cause of power outage } & & \\
\cline { 3 - 7 } & & Component Failure & Maintenance & Windy Rain & Animal Contact & Fallen tree \\
\hline 1 & Sheno (15kV) & 70 & 65 & 20 & 20 & 30 \\
2 & Enwary & 68 & 62 & 22 & 25 & 34 \\
3 & Aliu -Amba & 60 & 59 & 24 & 26 & 36 \\
4 & Ankober & 62 & 67 & 25 & 30 & 33 \\
\hline
\end{tabular}

\section{Reliability Analysis of Power Distribution Systems}

The existing power distribution in Debre Berhan town is radial distribution system type. This means the power is delivered to the customer from the utility in a one path way. There are no laterals and interconnection or mesh type network topology. Even though radial power distribution system is less costly in terms of design and protection, it's vulnerable to disturbance hence less reliable. Because of its radiality this substation has a frequent interruption to the customer. Due to this reason the mesh or interconnected distribution is highly recommended to improve customer based reliability and power availability. Debre Berhan substation has seven outgoing feeders. It works in $15 \mathrm{kV} \& 33 \mathrm{kV}$ voltage level in the secondary side of the substation transformer.

\section{Modeling of Debre Berhan Distribution Network for Base Case Using ETAP Software}

ETAP software is a powerful electrical engineering analysis and management tools established at a world leader in power system design analysis and monitoring. The Electrical Transient Analyzer Program (ETAP) is used as the analytical tool [7]. To model the system with ETAP software Sheno $(15 \mathrm{kV})$ feeder is selected. This feeder is selected from the other feeders because the unknown cause to failure recorded is higher than the other feeders as shown in Table 1. To calculate the failure rate of each component in the feeder for active failure rate and passive failure rate the fault rate data and its cause are required. In order to model the feeder the cumulative load, sample feeder line, for each type of transformer one sample and other component and devices are modeled. The reliability analysis and assessment using ETAP software for radial and looped systems is a very efficient analytical algorithm. The algorithm is used based on the reliability evaluation and component modeling presented in probabilities all listed below in equations. To model distribution system reliability analysis the following assumptions are considered:

a) Only AC systems are considered.

b) Switching devices can be opened whenever possible to isolate a fault.

c) All switching devices operate successfully.

d) All failures are statistically independent.

The reliability indices which are used to calculate for each component in component modeling are expressed as follow:

1) Expected Failure Rate $(\lambda)$ :

$$
\text { Expected Failure Rate }(\lambda):=\frac{\text { number of outage on component in a given time }}{\text { total time component in operation }}
$$

$\lambda$ is the frequency of load interruption per year. As shown in equation. It is the sum of the active failure rate $\left(\lambda_{A}\right)$ and passive failure rate $\left(\lambda_{\mathrm{p}}\right)$. Active failure rate causes the operation of the protection device around the failed component (like short-circuit fault) or is the failure of the component itself that restore services after replacement.

2) Mean time to repair (MTTR) (r): $r$ is the time (hours) required to repair a component outage and/or restore the system in to normal operating state,

$$
\mathrm{MTTR}=\mathrm{r}
$$

3) Expected Repair Rate $(\mu): \mu$, is the frequency of a repair

$$
\mu=\frac{8760}{\mathrm{MTTR}}
$$

4) Mean Time to Failure (MTTF):

MTTF is expected time (years) that the component will be in failure.

$$
\mathrm{MTTF}=\frac{1}{\lambda}
$$

5) Mean Time Between Failure (MTBF)

MTBF is the expected time (years) between a component failure. 


$$
\mathrm{MTBF}=\mathrm{MTTF}+\frac{\mathrm{MTTR}}{8760}
$$

6) Forced Outage Rate (FOR)

The basic parameter used is the probability of finding the component on forced outage at some distant time in the future. Its unavailability is evaluated from the previous indices equation, forced outage rate:

$$
\mathrm{FOR}=\mathrm{U}=\frac{\mathrm{MTTR}}{8760 * \mathrm{MTTF}+\mathrm{MTTR}}=\frac{\mathrm{MTTR}}{\mathrm{MTBF}} * 8760
$$

7) Expected Energy not supplied index at load point (EENS),

$$
\text { EENS }=\sum_{i}^{n} \text { Lai. Ui }
$$

Where Lai, and $U_{i}$, are the average connected load and the average annual outage time at load point i respectively.

8) Expected interruption cost index at load point (ECOST):
9) ECOST is the cost of not supplied energy at that load point. Interrupted Energy assessment Rate index at load point $\{\operatorname{IEAR}(\$ / \mathrm{KWh})\}$.

$$
\mathrm{IEARi}=\frac{\mathrm{ECOST} \mathrm{i}}{\mathrm{EENS}}
$$

The IEAR is important index in order to identify the weak points of the network. The failure rates and repair duration of different components such as transformers feeder circuit breakers, bus bars, feeder lines, isolators and fuses are summarized with the simulation result in table 3 below.

Figure 1, illustrates the existing system modeling for Sheno $(15 \mathrm{kV})$ feeder in Debre Berhan Distribution Network using ETAP software. Based on the above mathematical equations ETAP software can execute the reliability indices. In this figure all the feeder components are clearly modeled with the given software.

$$
\mathrm{ECOSTi}=L i \sum_{j \notin N e}^{n} \mathrm{f}(\mathrm{rij}) * \lambda \mathrm{ej}
$$

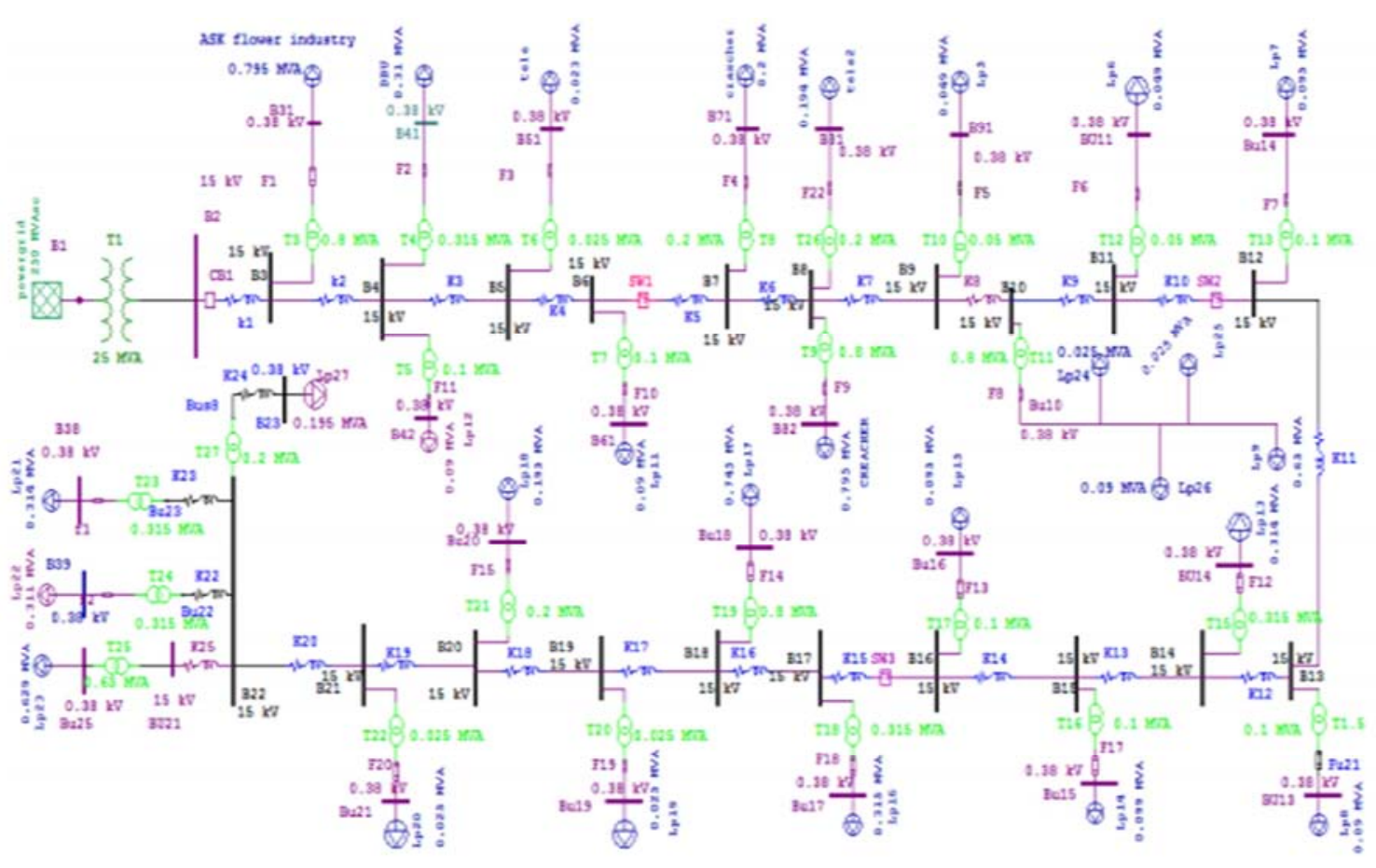

Figure 1. Modeling of Sheno Feeder with ETAP software.

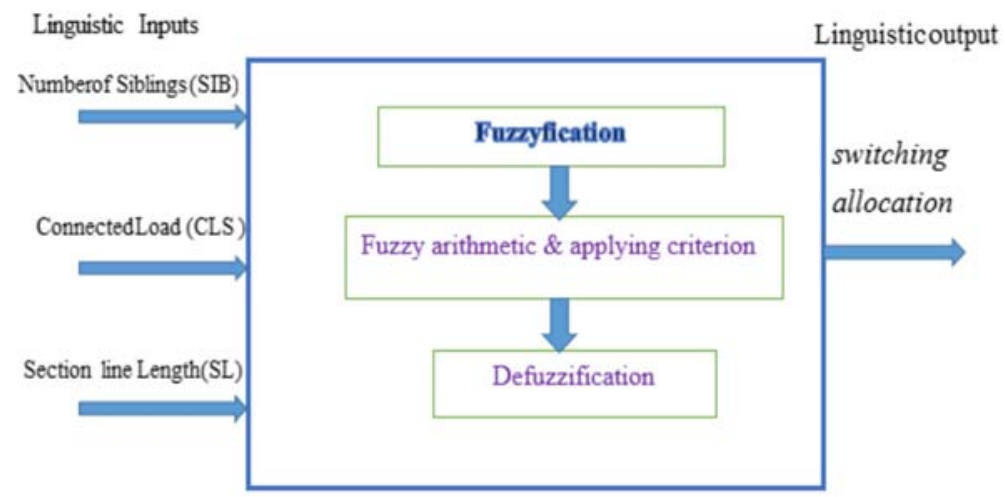

Figure 2. Fuzzy Logic Control for Benefit of Switching Allocation. 


\section{Fuzzy Logic System for Determination and Allocation of Optimal Number of Sectionalizing Switches}

Fuzzy modeling is the method of describing the characteristics of a system using fuzzy inference rules. The method has a distinguishing feature in that it can express linguistically complex non-linear system [8]. The Fuzzy logic system (FLS) is a logic system which represents reasons and knowledge, a fuzzy manner for reasoning under uncertainty or describes in imprecise manner for human interpretation [9].

\subsection{Suitability of Switches Allocation Optimization Problem}

Proposed method: The proposed Fuzzy Logic Controller optimization for benefit of switching allocation in Sheno $(15 \mathrm{kV})$ feeder consists of three Linguistic Inputs i.e.

1. Number of branches connected to each bus (NBC)

2. Connected Load to the line segment (CLS) \&

3. Section line Length (SLB)

All the above input variables generate one output variable i.e. benefit of switching allocation. The proposed Fuzzy Logic Controller inference engine is designed using 27 rules. Every Linguistic inputs and outputs has a set of membership functions [10]. The MF used for all inputs and output are trposod membership function (MF). The objective function is to minimize the total interruption cost given in (equation-14), subject to the following two constraints:

1) The system is still radially operated and
2) All the load points are still electrically supplied.

$$
\begin{aligned}
\text { Minimize }= & \mathrm{ECOST}_{\mathrm{i}}=\mathrm{Li} \sum n j £ N e \mathrm{f}(r i j) \\
& \text { Cost benefit }=\mathrm{ECOST}_{\mathrm{i}}-\mathrm{FC}
\end{aligned}
$$

Where $\mathrm{FC}=$ Switching Installation Cost

The FES contains a set of rules, which are developed from qualitative descriptions [9, 11]. The Fuzzy Expert System (FES) was developed to solve specialist human tasks, inside a specific knowledge domain. The heuristic knowledge about a system can be used to help to build a good project. In this paper, a FES is used to evaluate the benefit of switch installation in the given of a feeder sections [10-15]. The FES applied to solve this problem has the follows input variables as shown in the Figure 4.

Number of branches connected to each bus (NBC): This is a normalized measure of the branching that is occurring that is occurring at the beginning of the section being considered as shown in Figure 3.

1) Connected Load to the line segment (CLS): This is a normalized measure of how much load is connected to the section being considered as shown in Figure3.

2) Section Length between each bus (SLB): This is a normalized measure of the length of the section between bus bars are being considered. In the representation of the input variables were used five tram fuzzy sets: very low, low, medium, high and very high. As shown in Figure4.

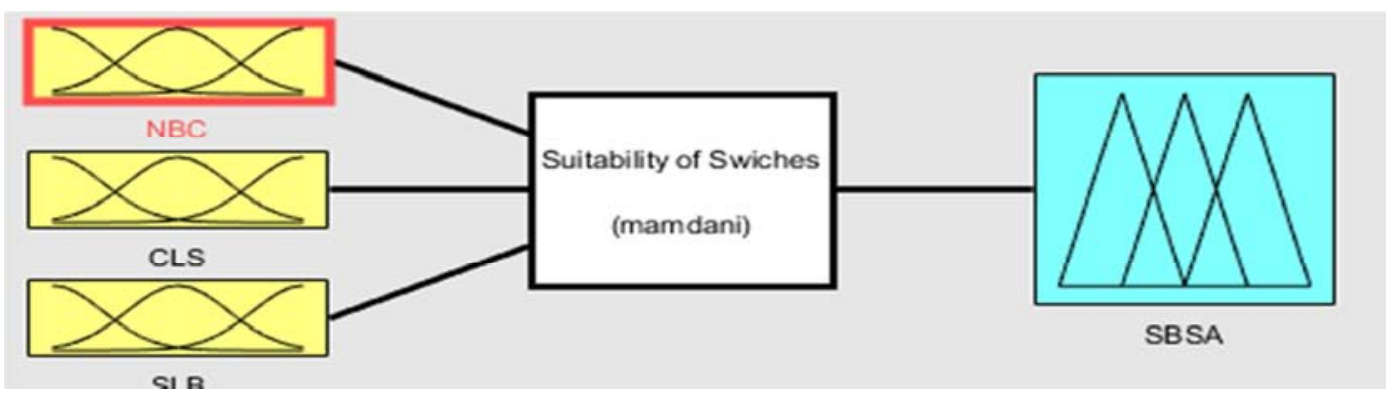

Figure 3. Fuzzy inference system for switches allocation.

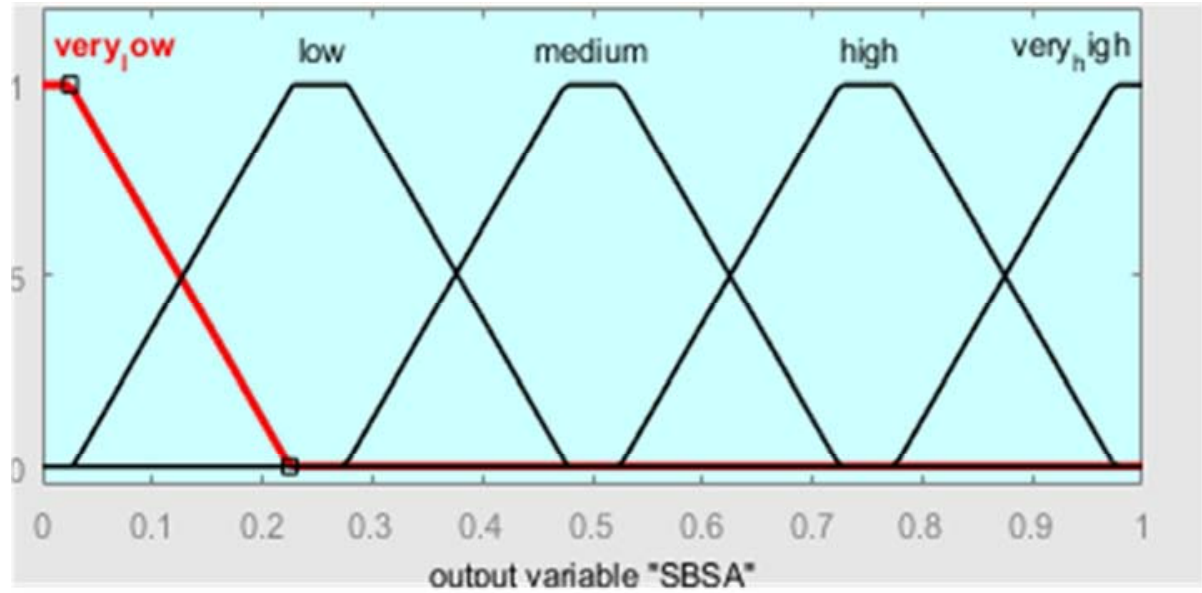

Figure 4. Membership function for Switching Allocation. 
Figure 4 shows the output variable that represents the suitability of switch installation for a particular section (SBSA), is formed by five trposod fuzzy sets: very low, low, medium and high and very high. The figure 6 shows the fuzzy sets to the output variable. It was assumed that BEN index must be greater than 0.55 for sectionalizers switches placement. Where SBSA is Suitability of Switch of Switch
Allocation. Output value $\left(\mathrm{M}_{\mathrm{i}}\right)$, which is a number in the interval between 0 and 1 . This value is evaluated for every section of the network and represents the worth of installing a switch in this section. In the inference process, every input variable (that is originally non-fuzzy) is converted into a fuzzy.

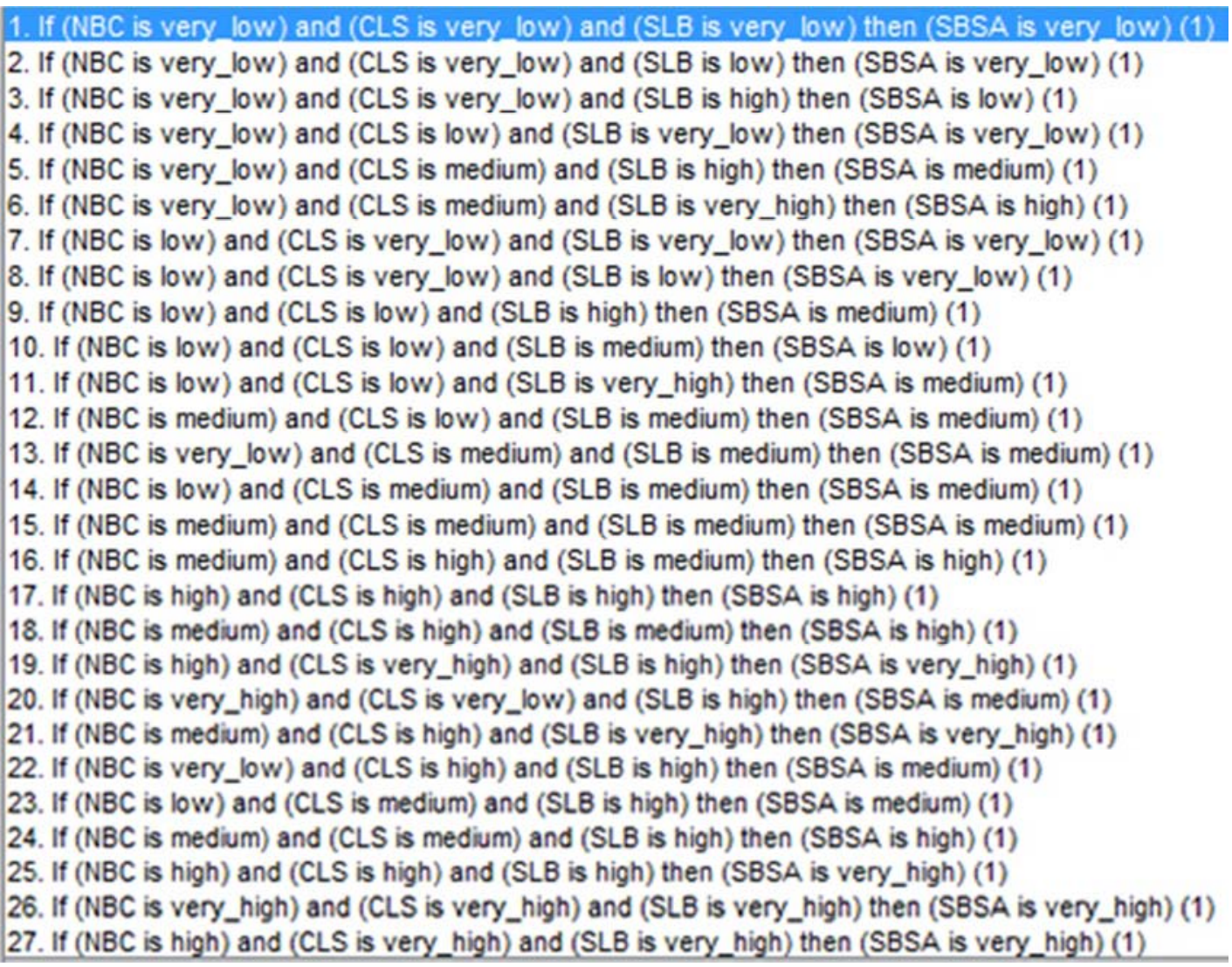

Figure 5. The Rule Created for Suitability of Switch Allocation using Matlab Software.

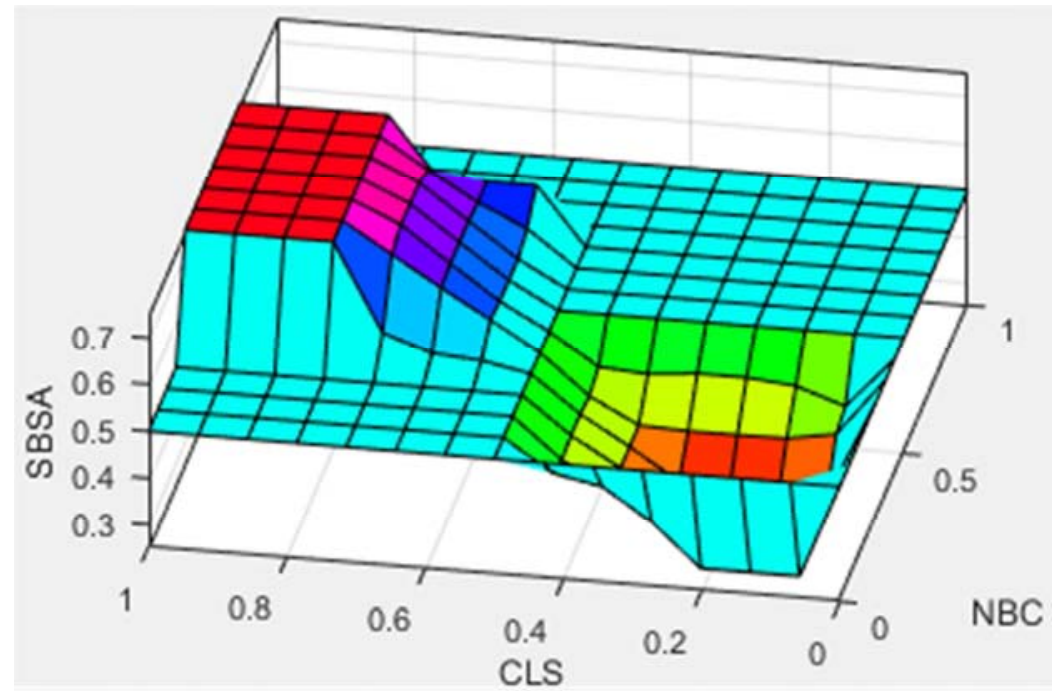

Figure 6. Surface Viewer for Switch Allocation. 


\subsection{Rule Viewers for Suitability of Switches Allocation Optimization Problem: Proposed Method: The Proposed Fuzzy Logic Controller}

After defining the fuzzy sets to the input and output variables, the fuzzy rules must be generated for the Fuzzy Inference System. Fuzzy inference is used to determine the values based on the fuzzy sets that represents the input variables. Figure 6 illustrated that the suitability of switching installation i.e. the surface viewer shows that the flat higher surface indicated the requirement of sectionalizers switches are high. This figure shows that the surface area of switch allocation optimization fuzzy logic tool box indicating that the higher flat surface need to install the switch on that section.

The rule base can also be displayed graphically as shown in Figure 7. The red line on each input side are, $0.5,0.5 \& 0.5$ indicates the value of the input. Similarly the bar on the most right hand side, indicates the output value, 0.5 . On the left-hand side you can see the input, SIB, CLS and SLB and on the right side output, SBSA. There are three rules and the corresponding triangular membership functions displayed. In the right-hand side lower corner is the result of fuzzy reasoning. At this point it is a fuzzy set. Applying defuzzification method, in the Figure 7 center of gravity has been chosen, a crisp value is obtained. Different input values can be tried by moving the red, vertical line on the left-hand side on as shown in Figure 7. This figure primarily states that the relationship among the three inputs and the output that where the is best location of switches on the given feeder. It can also determine the order of locations need to be installed.

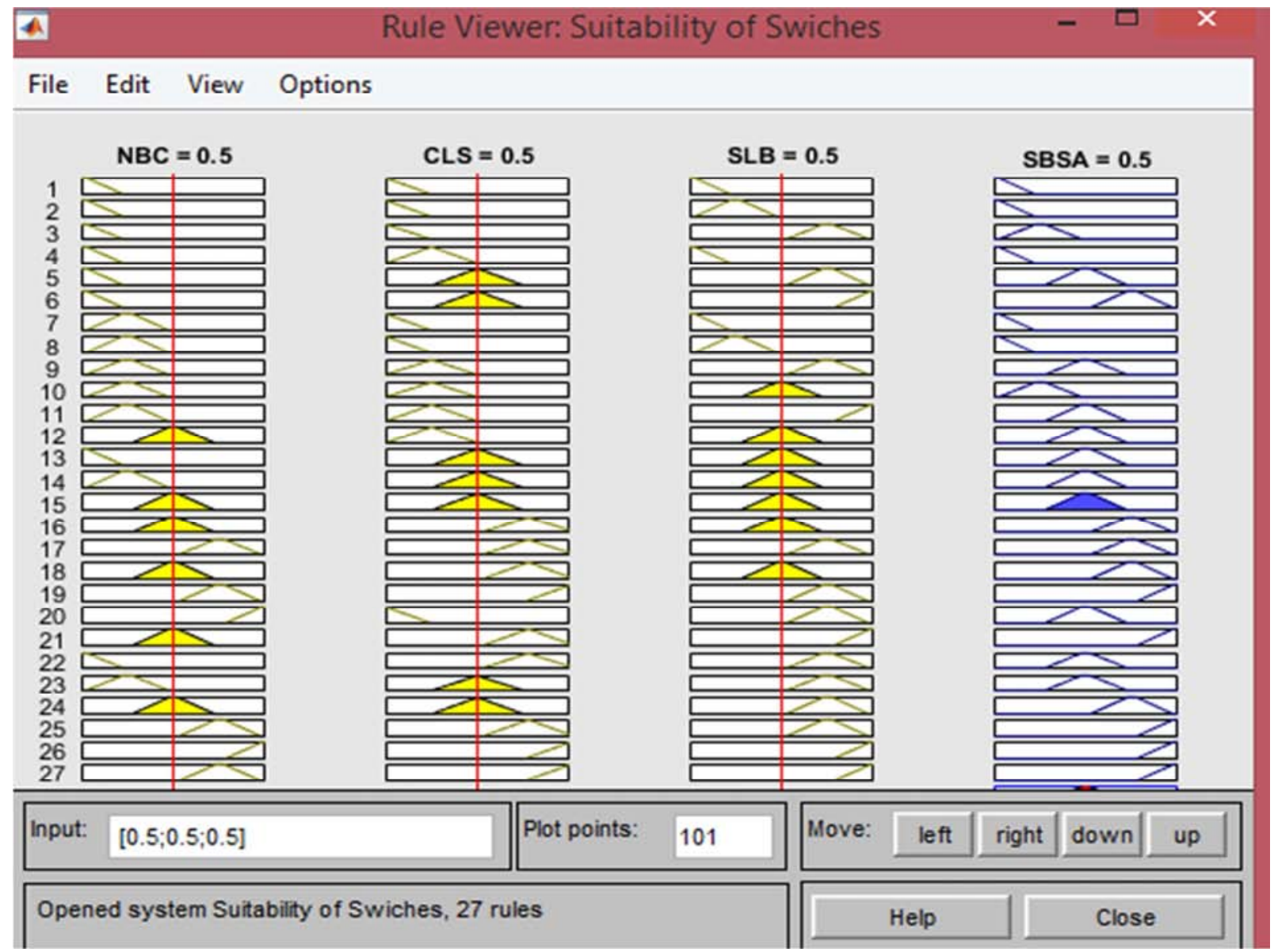

Figure 7. Rule Viewer for Allocation of Switches.

Table 2. Number of Transformers and Rating of Each Transformer.

\begin{tabular}{|c|c|c|c|c|c|c|c|c|c|c|}
\hline \multirow{2}{*}{ Feeder's Name } & \multicolumn{10}{|c|}{ Capacity (KVA) } \\
\hline & $25 \mathrm{KVA}$ & $50 \mathrm{KVA}$ & $100 \mathrm{KVA}$ & $160 \mathrm{KVA}$ & 200 KVA & 315 KVA & $630 \mathrm{KVA}$ & 800 KVA & $1250 \mathrm{KVA}$ & Total \\
\hline Sheno (15kv) & 3 & 2 & 8 & - & 4 & 5 & 2 & 3 & - & 27 \\
\hline Enwary & 6 & 10 & 5 & - & 14 & 1 & - & - & 1 & 37 \\
\hline Aliu- Ameba & 5 & 8 & 6 & - & 5 & & 1 & 1 & - & 26 \\
\hline Ankober & 3 & 10 & 5 & - & 13 & & & & & 31 \\
\hline
\end{tabular}

As shown in Table 2 above illustrated different rating of transformers are available in Debre Berhan distribution system.
This Table data were taken from Debre Berhan distribution system district itself recorded. These different rating of 
transformers are used for different types of load centers.

The fuzzy logic optimization technique has been evaluated with the variable of section line length, total connected load and number of branches connected to a single bus. These variables have clearly shown in the Table 3 below. This table shows that the greater SBSA index indicated the optimal places in which sectionalizers switches are required for the given Sheno $(15 \mathrm{KV})$ test feeder.

Table 3. The output of fuzzy logic optimization by using MATLAB software.

\begin{tabular}{|c|c|c|c|c|c|c|}
\hline $\begin{array}{l}\text { Section } \\
\text { number }\end{array}$ & Length & $\begin{array}{l}\text { Normalized value } \\
\text { length }\end{array}$ & $\begin{array}{l}\text { Connected load } \\
\text { (KVA) }\end{array}$ & $\begin{array}{l}\text { Normalized Value of } \\
\text { KVA }\end{array}$ & $\begin{array}{l}\text { Normalized number of } \\
\text { branches }\end{array}$ & BEN index \\
\hline $\mathrm{L} 1$ & 0.45 & 0.100 & 0 & 0.000 & 0.2 & 0.09 \\
\hline L2 & 0.05 & 0.011 & 630 & 0.788 & 0.4 & .5 \\
\hline L3 & 1.5 & 0.333 & 415 & 0.519 & 0.2 & 0.408 \\
\hline L4 & 4.5 & 1 & 100 & 0.125 & 0.2 & 0.5 \\
\hline L5 & 2.5 & 0.556 & 25 & 0.031 & 0.2 & 0.5 \\
\hline L6 & 4.45 & 0.989 & 315 & 0.394 & 0.4 & 0.581 \\
\hline L7 & 2.95 & 0.656 & 800 & 1.000 & 0.4 & 0.88 \\
\hline L8 & 2.1 & 0.467 & 400 & 0.500 & 0.2 & 0.466 \\
\hline L9 & 4.4 & 0.978 & 800 & 1.000 & 1 & 0.887 \\
\hline L10 & 0.75 & 0.167 & 50 & 0.063 & 0.2 & 0.103 \\
\hline L11 & 0.15 & 0.033 & 100 & 0.125 & 0.2 & 0.232 \\
\hline L12 & 2.95 & 0.656 & 800 & 1.00 & 0.2 & 0.880 \\
\hline L13 & 0.45 & 0.100 & 100 & 0.125 & 0.2 & 0.0946 \\
\hline L14 & 0.25 & 0.056 & 100 & 0.125 & 0.2 & 0.375 \\
\hline $\mathrm{L} 15$ & 1 & 0.222 & 100 & 0.125 & 0.2 & 0.115 \\
\hline L16 & 0.45 & 0.100 & 315 & 0.394 & 0.2 & 0.469 \\
\hline L17 & 2.8 & 0.656 & 800 & 1.000 & 0.2 & 0.582 \\
\hline L18 & 0.3 & 0.067 & 25 & 0.031 & 0.2 & 0.152 \\
\hline L19 & 0.25 & 0.056 & 200 & 0.250 & 0.2 & 0.291 \\
\hline L20 & 4.45 & 0.989 & 630 & 0.788 & 1 & 0.887 \\
\hline L21 & 4.4 & 0.978 & 25 & 0.031 & 0.2 & 0.325 \\
\hline L22 & 0.8 & 0.178 & 315 & 0.394 & 0.2 & 0.324 \\
\hline L23 & 0.15 & 0.033 & 315 & 0.394 & 0.2 & 0.325 \\
\hline L24 & 2 & 0.444 & 200 & 0.250 & 0.2 & 0.291 \\
\hline L25 & 0.45 & 0.100 & 630 & 0.788 & 0.2 & 0.333 \\
\hline
\end{tabular}

This result in table 3 is the basic result that determines the location of selected section for sectionalizer switches that depents on the main factors parametrs of the distribution system in in large. These varibles are the most domination factor of the reliability of distribution ssyetem.

\section{Simulation Studies and Analysis of Results}

Most of loads in Debre Berhan town are supplied from a single substation. The monthly interruption duration and frequency of the system were taken from four feeders. The power interruptions of each feeder is recorded when the outgoing circuit in the substation breaker is open, when all customers connected to the feeder are interrupted. The interruptions occurred at each load point of transformer connection point and service line of customers is not included.

The number of power outages and durations of each feeder for the year of 2017 is summarized as shown in Figure 9. Based on the recorded data the average reliability indices of the existing system are calculated and summarized in Figure 9. It shows average reliability indices, like SAIFI, SAIDI, CAIDI, ASAI and ASUI CAIDI values are also calculated for the year 2017.

Figure 10 show that the analytical calculated system reliabity indices for all four feeders. As it was clearly seen in Sheno feeder there has been a frequent interruption and hence there was an interest to apply improvement method.

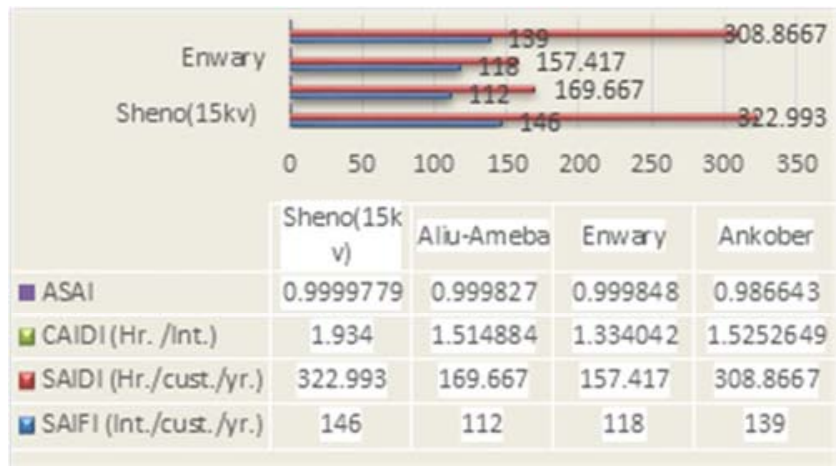

Figure 8. Four Feeders Reliability Indices in 2017 GC.

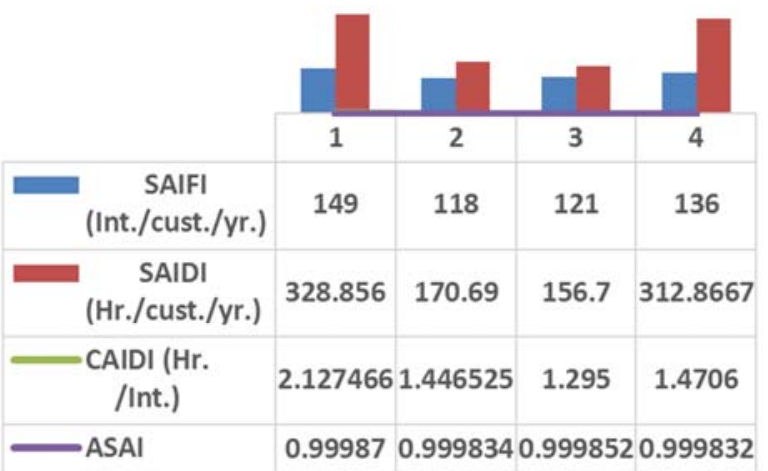

Figure 9. Feeders Reliability Indices in 2018 GC. 


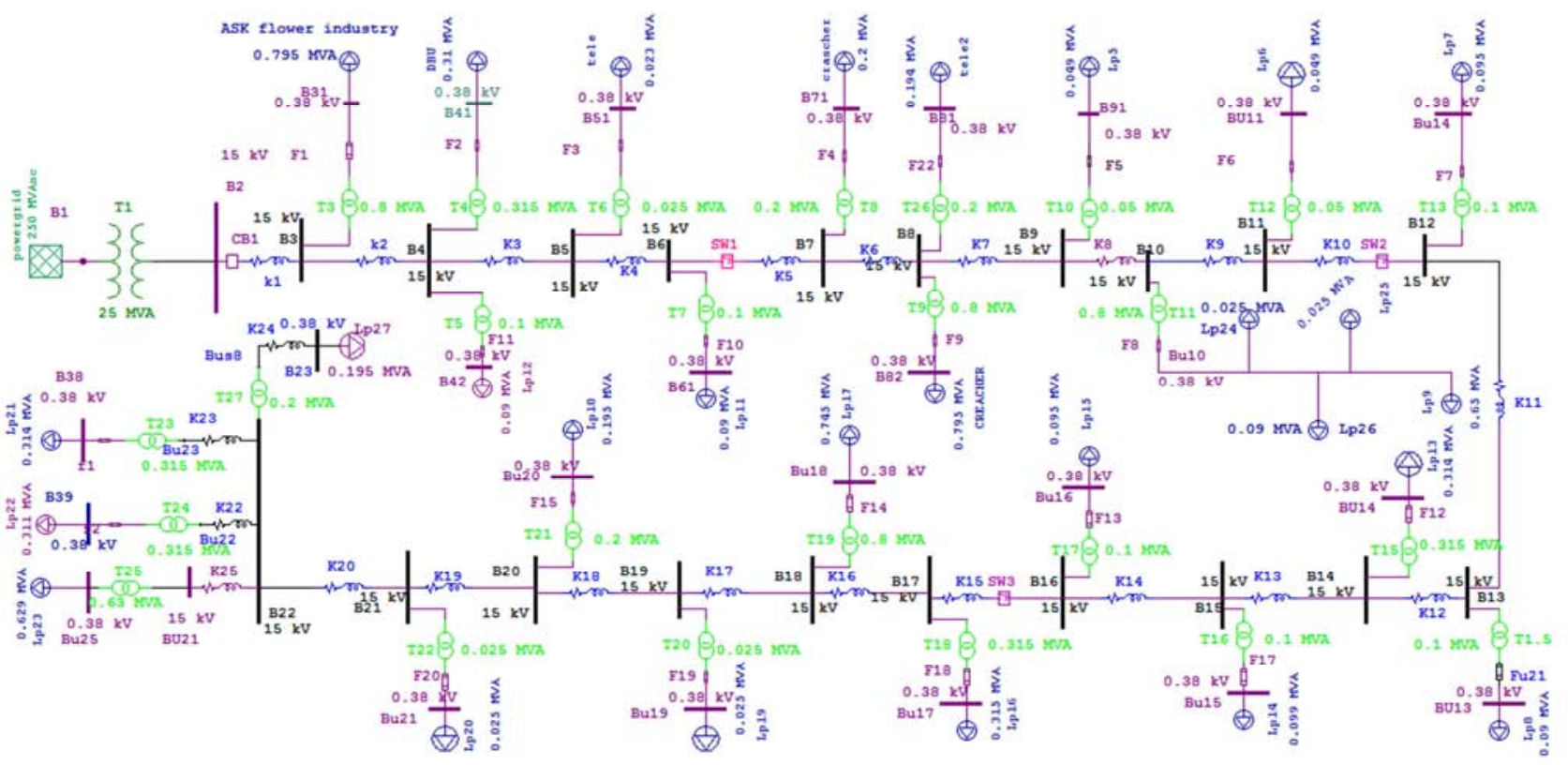

Figure 10. Existing Sheno (15kv) Feeder Configuration.

The exiting Sheno feeder is modeled and simulating the reliability assessment to known how much the system reliability is poor or good as indicated in figre10. The simulation result of reliability shows the exiting feeder modeled with ETAP software was very poor and need to be improved.

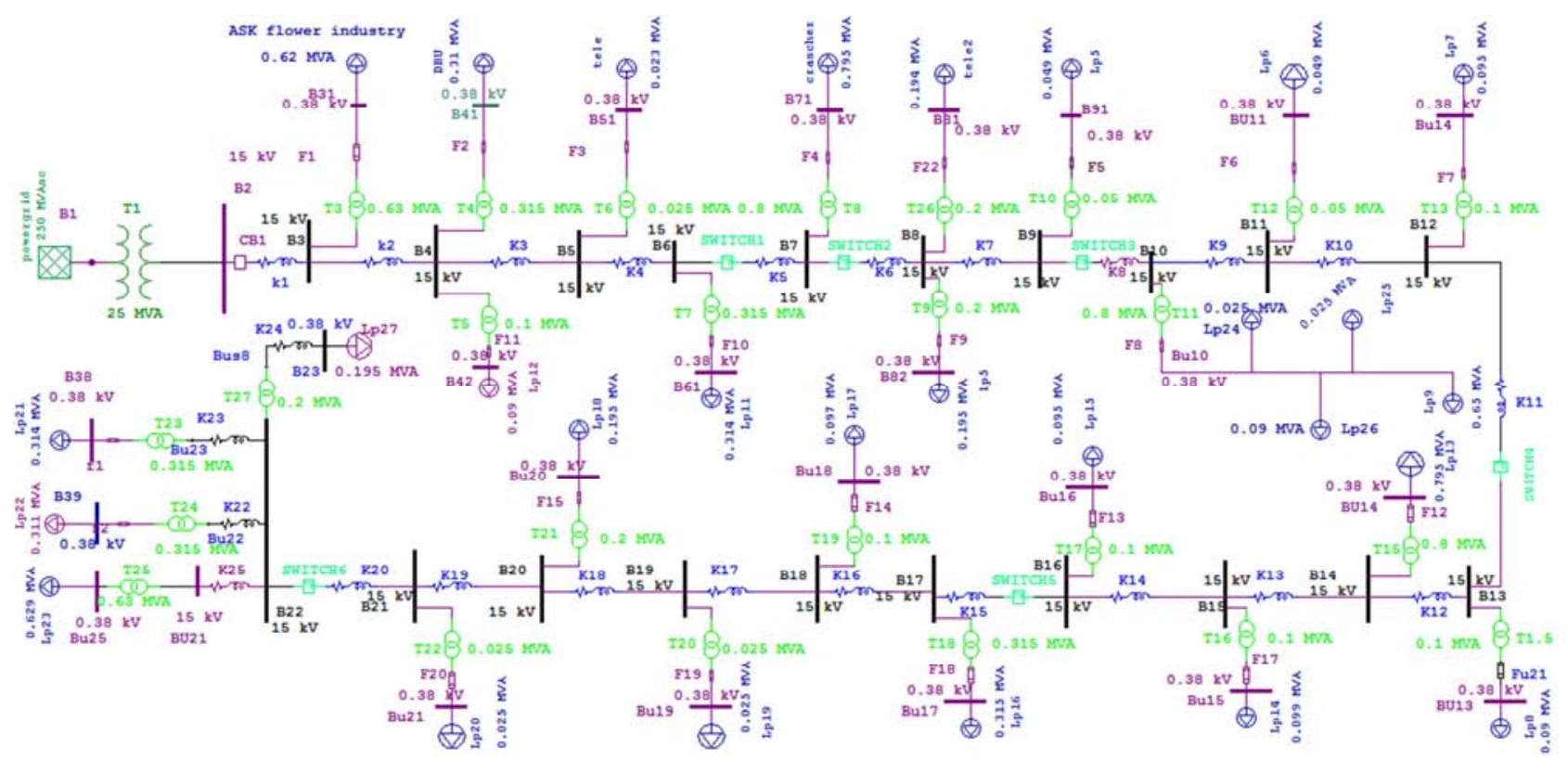

Figure 11. Optimal Sheno (15KV) Feeder Configuration.

Table 4. Sector Interruption Cost Result.

\begin{tabular}{lll}
\hline Sector Interruption Cost & & \\
\hline \multirow{3}{*}{ Sector Name } & Interruption & Cost \\
\cline { 2 - 3 } & Duration & $\mathbf{\$} \mathbf{k W}$ \\
\cline { 2 - 3 } & Minutes & 0.06 \\
Agricultural & 1.00 & 0.34 \\
& 20.00 & 0.65 \\
& 60.00 & 2.06 \\
& 240.00 & 4.12 \\
Commercial & 480.00 & 0.38 \\
\hline
\end{tabular}




\begin{tabular}{lll}
\hline Sector Interruption Cost & & \\
\hline \multirow{3}{*}{ Sector Name } & Interruption & Cost \\
\cline { 2 - 3 } & Duration & $\mathbf{S / \mathbf { W }}$ \\
\cline { 2 - 3 } & Minutes & 2.97 \\
& 20.00 & 8.55 \\
& 60.00 & 31.32 \\
& 240.00 & 83.01 \\
Govt. \& Inst. & 480.00 & 0.04 \\
& 1.00 & 0.37 \\
& 20.00 & 1.49 \\
Industrial & 60.00 & 26.04 \\
& 480.00 & 1.63 \\
& 1.00 & 3.87 \\
& 20.00 & 9.09 \\
& 60.00 & 25.16 \\
& 240.00 & 55.81 \\
& 480.00 & 9.88 \\
& 20.00 & 21.06 \\
& 60.00 & 68.83 \\
& 240.00 & 119.20 \\
\hline
\end{tabular}

Figure 10 illustrated that the exciting system of Sheno feeder modeling of electrical transient analyzer program (ETAP) software with only three sectionalizers switches.

As shown in Figure 11 the optimal number of sectionalizers switches have been optimized to six switches that means three additional switches are important to the given test feeder. The number of switches and the locations were determined using the fuzzy logic optimization technique and the reconfiguration of the network results are presented in Figure 11. The simulation result of the figure is stated in table table 5 which is relatively reliable.

As shown in Table 4, reliability cost can be quantified in forms of customer interruption costs. Customer interruption costs provide an indirect measure of monetary losses associated with a power interruption and are served as input data for cost implications and worth assessments of system planning and operational decisions. The calculation of customer interruption costs requires distribution reliability indices of the load points and customer interruption cost data and simulating using ETAP software. Customer interruption cost data, compiled from customer surveys, are used to develop a sector customer damage function (SCDF). The SCDF is a function of customer class and outage duration, which can be used to estimate monetary loss incurred by customers due to power failure. The above result shows the SCDF for seven sectors customers for five discrete outage durations. The outage cost generated using ETAP software.

Sensitivity Analysis For Expected Energy Not Supplied (EENS)

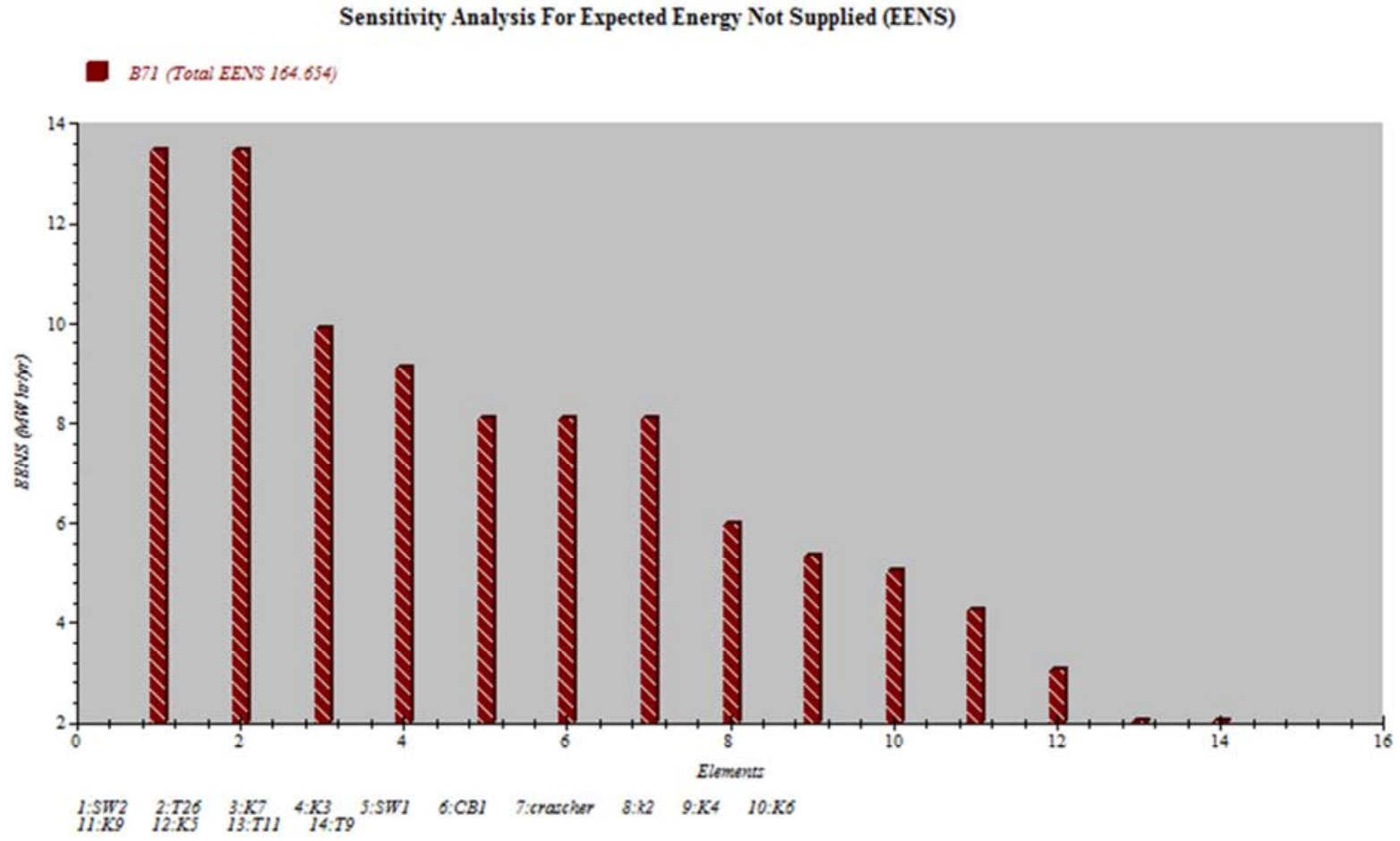

Figure 12. EENS Simulated Result for Sheno (15kv) Feeder. 


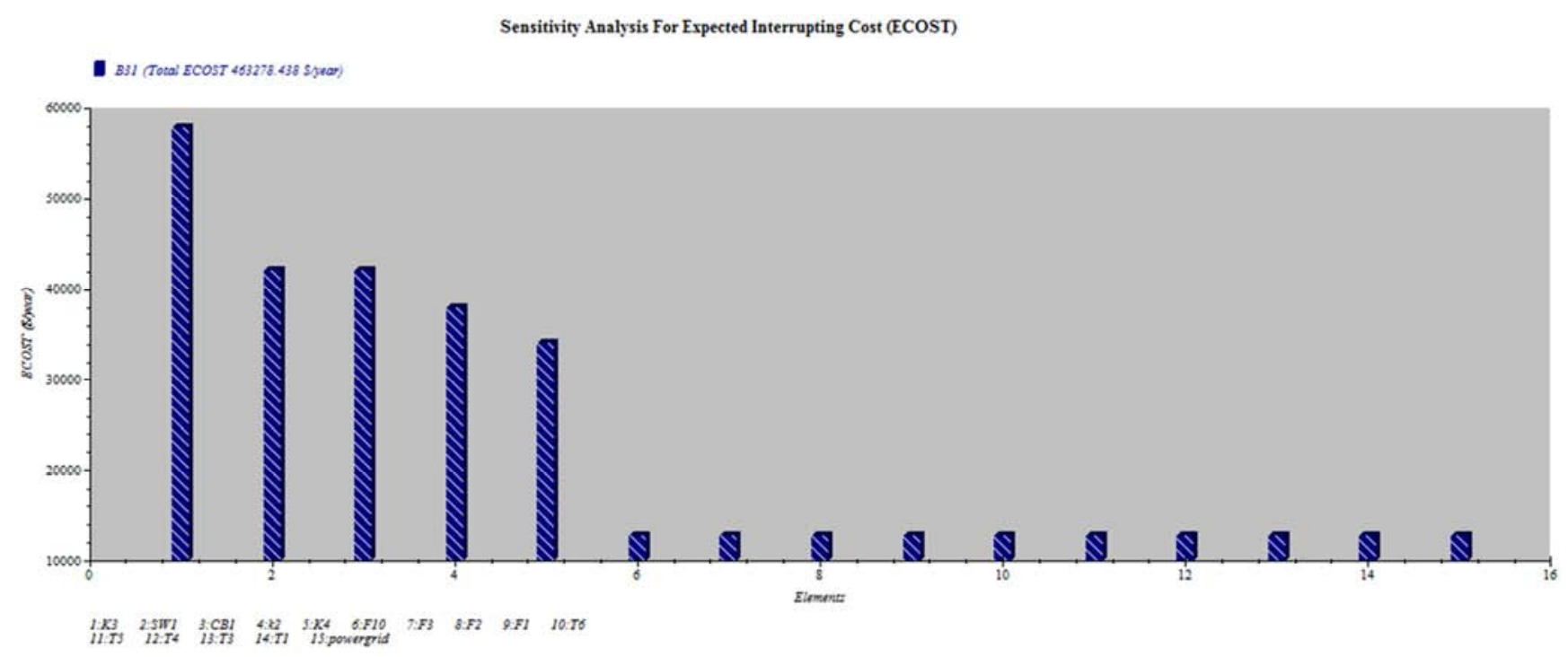

Figure 13. ECOST Simulated Result for Sheno (15kv) Feeder.

ETAP software generated the plot that indicated the ranking order of the components contributing to different outages. As shown in Figure 13 above the components are shown their ranking order SW2, T26, K7, K3, SW1, CB1etc indicated that the ranking of order of components which are contributing to the total expected energy not supplied. This ranking order of the component is used to take the measure of actions (EENS). Figure 13 shows SW2, T26, line 7, SW1and CB1 are components which were contributing for EENS due to an expected frequent power interruptions.

Table 5. Comparision of Different Case for Sectionalizers Switch Placement.

\begin{tabular}{|c|c|c|c|c|}
\hline $\begin{array}{l}\text { Reliability } \\
\text { indices }\end{array}$ & $\begin{array}{l}\text { Case-1: Without switch of } \\
\text { Sheno feeder }\end{array}$ & $\begin{array}{l}\text { Case-2: Initial configuration of Sheno feeder } \\
\text { (base case) }\end{array}$ & $\begin{array}{l}\text { Case-3: Optimal configuration } \\
\text { Of Sheno feeder }\end{array}$ & $\begin{array}{l}\text { Improve } \\
\text { ment }(\%)\end{array}$ \\
\hline SAIFI & $210.8677 \mathrm{f} /$ cust.yr & $145.2115 \mathrm{f} /$ cust.yr. & 132.7942 f / cust.yr & 8.55 \\
\hline SAIDI & 459.2445 hr. / cust.yr & 322.0554 hr. / cust.yr & 266.80474hr./cust.yr & 17.16 \\
\hline CAIDI & $2.178 \mathrm{hr}$. / Interruption & $2.218 \mathrm{hr}$. / Interruption & $2.009 \mathrm{hr}$. / cust. Int. & 9.4 \\
\hline ASAI & 0.9476 per unit & 0.9632per unit & $0.9695 \mathrm{pu}$ & 0.63 \\
\hline ASUI & 0.05243 per unit & 0.03676 per unit & $0.03046 \mathrm{pu}$ & 30 \\
\hline EENS & 2589.602 MWh./yr. & 1788.014 MWh./yr. & 1496.764 MWh./yr. & 15.73 \\
\hline ECOST & $19,376.84 \$ /$ yr. & $64,806.06 \$ / y r$. & $57,346.57 \$ /$ yr. & 11.5 \\
\hline
\end{tabular}

The total interruption cost (ECOST is the measure of reliabity worth analysis. As shown in figure 8 , the components which of contributing for total interruption cost (ECOST) were line1, swich1, CB1and line 2 respectively. This figure shows the ranking order of the components to contribute the failure of the given feeder test feeder. From this result we can know the components performance against an expected power interruption.

As shown in Table 5, three cases have been compared such as: case one if there was no any sectionalizers switch, case 2 was the existing system (base case) which has three sectionalizers switch and the third case was the optimal system or the optimal number of switches which were optimized to six number of Sectionalizers switches for the given test feeder. After optimal placement of sectionalizers switches the average system unavailability index (ASUI) is improved by about $30 \%$. Not only ASUI the other reliability indices have clearly illustrated in Figure 5 improved as compared with the base case and no sectionalizers switch conditions.

\section{Conclusion}

The reliability improvement techniques suggested as predictive reliability can minimize the power outage frequency and duration. The improvement has great impact socially and economically both for the utility and customers. This research seeks to model the impact of optimal number and placement of switches to the distribution system reliability. The reliability assessment in this work carried out with analytical approach and ETAP software simulations.

To solve the problem of optimal number of switch allocation, fuzzy expert system (FES) optimization method is selected. To illustrate the performance of the proposed algorithm, an actual Sheno $(15 \mathrm{kV})$ feeder of Debre Berhan distribution system was selected as the test system. To assess and evaluate reliability of the system analytical and simulation methods are implemented for the Sheno $(15 \mathrm{kV})$ feeder and the value obtained by analytical methods for SAIFI, SAIDI and CAIDI are 146.5 Failure /cust.yr, 325.8945 hr. /yr., and 2.209 respectively, similarly by simulation method the value obtained are 145.2115 Failure /cust.yr., $322.0554 \mathrm{hr}$. /yr. and 
2.218 which are almost the same; it approves that the reliability parameters (indices) analysis were properly modeled.

\section{Recommendations}

The quality and reliable power supply has a dominant factor in the development of the country socially and economically since, every technology used by customers is dependable on electrical power. To supply reliable and efficient power for the customers the power system networks could be planned, redesigned and reconnected by evaluating their past performance.

To achieve this goal reliability assessment is necessary for system planning based on reliability cost and worth assessment approach. It provides an opportunity to justify future system expansion and service improvement.

The following recommendations are given depending on practical observations and analysis on Debre Berhan town distribution system:

1) All Debre Berhan town distribution system feeders are connected in radial, purely radial feeders with no alternate supply capability are usually used for small loads or rural systems. Thus the connection scheme should be changed into open loop connection schemes.

2) As practically observed almost all protection device have no good covering and since the space between phases are narrow it can be shorted easily even by windy rain drops and a single leaves of trees which can be the main cause for power interruptions so they should have proper coverings.

3) The fuses are placed with their designed rated value to protect the system even direct connection is also done which is dangerous for the system though such visible mistakes must be avoided in the system.

\section{References}

[1] R. D. Nematollah Dehghani1, "Optimization of Recloser Placement to Improve Reliability by Genetic Algorithm," Energy and Power Engineering, 2011, 3, 508-512, doi: 10.4236/epe.2011.34061 Published Online September 2011 (http://www.SciRP.org/journal/epe), pp. 508-512, 2011.

[2] M. Ahmed, "Electric Power Distribution System Reliability Assessment Of Arba Minch City, Ethiopia," International Journal of Current Research, ISSN: 0975-833X, vol. 8, no. 08, pp. 36992-36995, 2016.

[3] M. A. K. a. D. A. Sharma**, "Reliability Enhancement of Power System by Condition Monitoring Transformer Using Fuzzy AHP," International Journal on Emerging Technologies, vol. 6 , no. 1, pp. 43-55, 2015.
[4] C. P. S. B. B. S. Atthapol Ngaopitakkul1, "A Reliability Impact and Assessment of Distributed Generation Integration to Distribution System," Energy and Power Engineering, doi: 10.4236/epe,54B199 Published Online July 2013 (http://www.scirp.org/journal/epe), vol. 5, pp. 1043-1047, 2013.

[5] S. S. M. Azhar Khan, "Reliability Based Power Distribution Systems," International Journal of Novel Research in Electrical and Mechanical Engineering, vol. 2, no. 1, pp. pp: (8-16), April 2015.

[6] K. V. Imayavaramban1 R. Karhikeyan2PG Scholar, 2Assistant Professor"Power System Reliability improvement by proper application of Problem Solving Tool," International Journal of Engineering and Techniques, Volume 1, Issue 2, March-April 2017, pp. 2395-1303.

[7] L. O. U. a. E. Udo, "Development of Outage Evaluation and Reliability Model for Benin City Power Distribution Network," American Journal of Engineering Research (AJER), vol. 6, no. 3, pp. 168-175, 2017.

[8] G. S. R. D. A. Srujana, "Transient Stability Improvement of Multi-machine Power System Using Fuzzy Controlled TCSC," International Journal of Advancements in Research \& Technology, Volume 1, Issue 2, July-2012, vol. 1, no. 2, pp. 2278-7763, 2012.

[9] D. M. *Lekshmi M1, "A Review on Electrical Power System Contingency Ranking Using Artificial Intelligence Techniques," IOSR Journal of Electrical and Electronics Engineering (IOSR-JEEE), vol. 12, no. 4, pp. 06-10, 2017.

[10] A. R. d. G. d. S. Tiago Alencar, "Switches Allocation In Distribution Network Using Particle Swarm Optimization Based On Fuzzy Expert System," in 17th Power Systems Computation Conference, Stockholm Sweden, August 2011.

[11] M. I. A. F. Yasser Gallal1, "Capacitor Allocation and Sizing for Distribution System via Fuzzy Technique," Global Advanced Research Journal of Engineering, Technology and Innovation (ISSN: 2315-5124) Vol. 2 (6) pp. 173-180, July, 2013, vol. 2, pp. 173-180, 2013.

[12] S Chandrashekhar Reddy, P. V. N. Prasad, A. Jaya Laxmi "Reliability Improvement of Distribution System: A Hybrid Approach Based on GA and NN" International Journal of Soft Computing and Engineering (IJSCE) 2231-2307, Volume-2, Issue-6, January 2013.

[13] Umar Abdi Geru "Reliability Analysis and Redesign of Power Distribution System (Case Study of Nazareth Distribution System)" International Journal of Innovative Science and Research Technology, 2456-2165, Volume 4, Issue 1, January 2019.

[14] "reliability assessment of distribution network with distributed generation based on bp neural network" paper open access, 2020 .

[15] Pragya Kirti Gupta, Rodolfo Martinsy, Saikat Chakarbartiz, Arya Devi Remanidevi "Improving Reliability and Quality of Supply (QoS) in Smart Distribution Network” 2016 IEEE. 